\title{
DYE TITRATIONS OF COVALENTLY CLOSED SUPERCOILED DNA ANALYZED BY AGAROSE GEL ELECTROPHORESIS
}

Robert J. DeLeys and David A. Jackson

Department of Microbiology

University of Michigan Medical School

Ann Arbor, Michigan, U.S.A. 48109

Received December 29,1975

SUMMARY: We have developed a rapid electrophoretic technique for performing ethidium bromide dye titrations in cylindrical $0.7 \%$ agarose gels. The technique was used to analyze the extent of supercoiling in circular covalently closed SV40, ColE1, and pSC101 DNA. We have estimated the superhelical densities of SV40, Co1E1, and PSC101 DNA to be $-0.050,-0.078$, and -0.085 respectively. The results obtained for native SV40 DNA correlate well with previously published values for the superhelical density of this DNA when these values are corrected to reflect a $26^{\circ}$ duplex unwinding angle for ethidium bromide. Ethidium bromide concentrations sufficient to partially relax a supercoiled DNA allow the DNA to be resolved into a series of discrete bands in agarose gels. The distribution of bands represents a natural heterogeneity in the superhelical densities of the DNA molecules in the population.

\section{INTRODUCTION}

The superhelical density of covalently closed aircular DNA has typically been analyzed by observing changes in the hydrodynamic properties or the density of the DNA as it binds increasing amounts of ethidium bromide. The methods most commonly employed are sedimentation velocity-dye titrations (1), viscometric titrations (2) and isopycnic banding in CsCl-dye solutions (3). The disadvantage of these techniques is that they are relatively complicated procedures which usually require expensive equipment and are rather time consuming. We have developed a technique whereby the conformational properties of a covalently closed circular DNA molelule can be observed at many dye concentrations simultaneously and have used the technique to determine the critical free dye concentration ( $\left.c^{\prime}\right)$ for three different DNAs. $C^{\prime}$ is that dye concentration at which the covalently closed molecule has the same hydrodynamic characteristics as the covalently open nicked circular molecule.

Agarose gel electrophoresis has been shown to be highly sensitive to DNA tertiary structure $(4,5)$ and will separate covalently closed superhelical 
DNA molecules from relaxed covalently open circular DNA molecules of the same molecular weight. The relaxation of supercoiled DNA by ethidium titration can thus be monitored in these gels. The migration of the DNA in a number of different ethidium concentrations can be tested in a single run so long as the ethidium is present only in the individual gels and not in the buffer chambers. Since ethidium is positively charged in the electrophoresis buffer, it will migrate towards the cathode whereas the DNA, which is negatively charged, will migrate towards the anode. The DNA w111 migrate at a rate determined by the shape of the molecule at the dye concentration within the gel. DNA will migrate in a steady-state ethidium concentration as long as electrophoresis is tcrminated before the ascending ethidium boundary, due to the absence of ethidium in the lower buffer chamber, reaches the leading DNA band. By using different ethidium concentrations in each gel, the entire titration may be performed in a standard 12-place cylindrical gel apparatus. We have used this method to determine $c^{\prime}$ for the DNAs of Simian Virus 40 (SV40), colicinigenic factor E1 (Co1E1), and plasmid pSC101. Espejo and Lebowitz have recently used a similar method for determining $c^{\prime}$ for SV40, PM2, and M13 RFI DNA.

\section{MATERIALS AND METHODS}

I. DNA

Covalently closed SV40 DNA [SV40(I)] was purified from CV-1 cells infected with SV40 at $0.01 \mathrm{pfu} / \mathrm{ce} 11$ by Hirt lysis (6), deproteinization of the Hirt supernatent with chloroform: isoamyl alcohol $(24: 1)$, isopycnic banding in CsC1ethidium bromide gradients, digestion with RNase A, and velocity sedimentation on $5-20 \%$ neutral sucrose gradients to remove oligomers.

Covalently closed ColEl DNA was prepared according to the procedure described by Clewell and Helinski (7) from E. coll strain JC411 (Co1E1) thy ${ }^{-}$ obtained from D. Clewel1. pSC101 DNA was purified from E. coli C600(pSC101) obtained from J. Morrow (8).

\section{Electrophoresis}

Electrophoresis was performed in cylindrical gels $(0.6 \times 15.0 \mathrm{~cm})$ of $0.7 \%$ agarose (Seakem) in $40 \mathrm{mM}$ TRIS, $5 \mathrm{mM}$ sodium acetate, $1 \mathrm{mM}$ EDTA adjusted to $\mathrm{pH} 8.2$ with acetic acid (electrophoresis buffer) in a 12 place apparatus. Gels containing ethidium bromide (Calbiochem) were prepared by adding aliquots of a stock solution of dye to molten agarose at $50^{\circ} \mathrm{C}$. Samples, consisting of $0.2-0.35 \mu g$ DNA in $25 \mu 1$ of electrophoresis buffer containing $5 \%$ sucrose and 
$0.5 \mu \mathrm{g} / \mathrm{ml}$ ethidium bromide, were run at $100 \mathrm{~V}(6.7 \mathrm{~V} / \mathrm{cm}$, about $3.2 \mathrm{~mA} / \mathrm{gel})$ for 105 minutes at room temperature. Where it was necessary to run more than 12 gels simultaneously, a second apparatus was wired to the same power supply to insure uniform conditions.

\section{Photography}

Gels were stained for 45 minutes in freshly prepared electrophoresis buffer containing $1 \mu \mathrm{g} / \mathrm{m} 1$ ethldium bromide (9). DNA was visualized by placing the gels over a long wave ultraviolet light source (C50 transilluminator, Ultraviolet Products). Photographs were taken with a Polaroid MP-4 camera using Polaroid Type $55 \mathrm{P} / \mathrm{N}$ film, a UV filter, and a Kodak No. 23A Wratten gelatin filter.

\section{RESULTS}

The success of the technique for determining $c^{\prime}$ in agarose gels relies on two conditions being fulf1lled. First, electrophoresis must be terminated before the leading DNA band and the ascending boundary of ethidium meet, since the migration of covalently closed DNA will be altered when the boundary is reached. Secondly, the DNA must equilibrate rapid1y with the ethidium in the gel. This second condition requires that the large amount of ethidium bound to the DNA in the sample dissociate rapidly and be removed from the DNA so that the DNA quickly is exposed to the steady-state dye concentration in the gel. We have detcrmined that this latter condition is met in this system in the following manner. Samples were prepared containing $0.35 \mu \mathrm{g}$ of a mixture of SV40(I) and nicked circular SV40 DNA [SV40(II)]. Ethidium bromide was added to each sample to give final concentrations ranging from zero to $200 \mu \mathrm{g} / \mathrm{m} 1$. The samples were layered onto $0.7 \%$ agarose gels containing no ethidium and electrophoresis was carried out as described. It was found that the migration of SV40(I) relative to SV40(II) was independent of the initial ethidium concentration in the sample, demonstrating that bound ethidium dissociates before any detectable alteration in migration can occur, even when the ethidium concentration in the sample is greater than $10^{4}$ times that required to relax SV40(I) completely.

Dye titrations of closed circular SV40, ColE1, and pSC101 DNA are shown in figures 1, 2, and 3. The ethidium concentration at which the covalently closed and nicked circular forms of the DNA comigrate is the critical free 


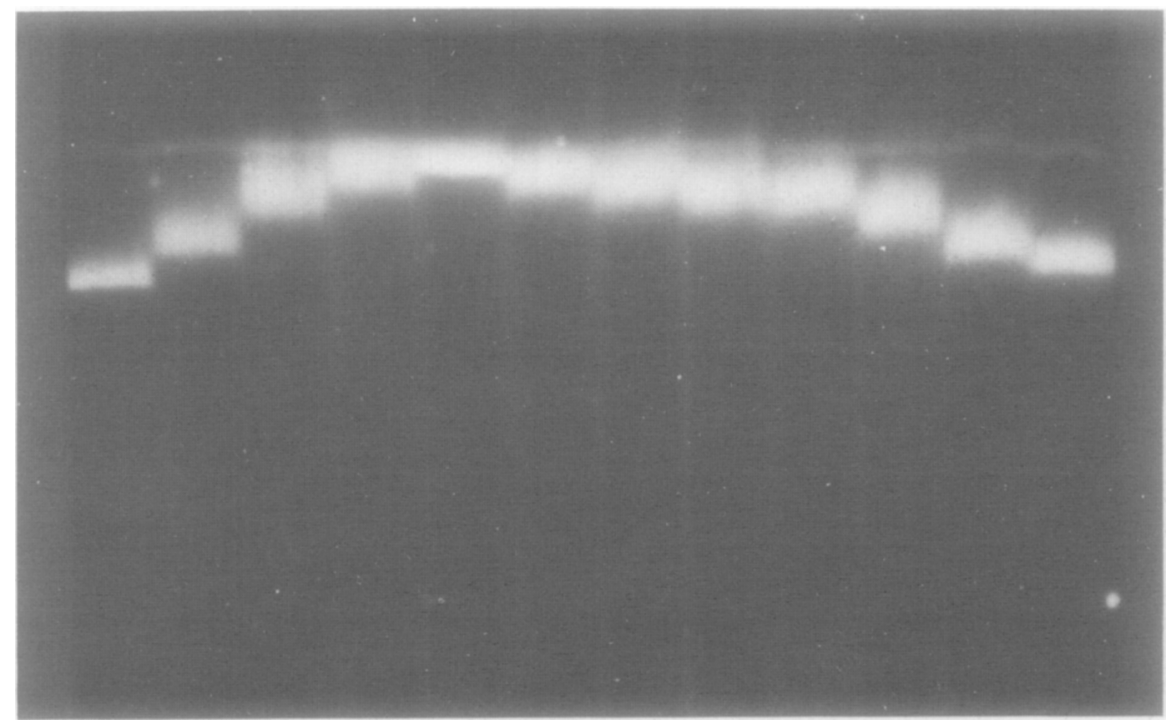

Figure 1: Dye titration of native SV40 DNA

Electrophoresis was performed as described in Materials and Methods. Direction of migration is from top to bottom. Ethidium bromide concentration increases from left to right from $0.01 \mu \mathrm{g} / \mathrm{ml}$ to $0.11 \mu \mathrm{g} / \mathrm{ml}$ in 0.01 $\mu \mathrm{g} / \mathrm{ml}$ increments. The gel on the extreme right contained no ethidium bromide.

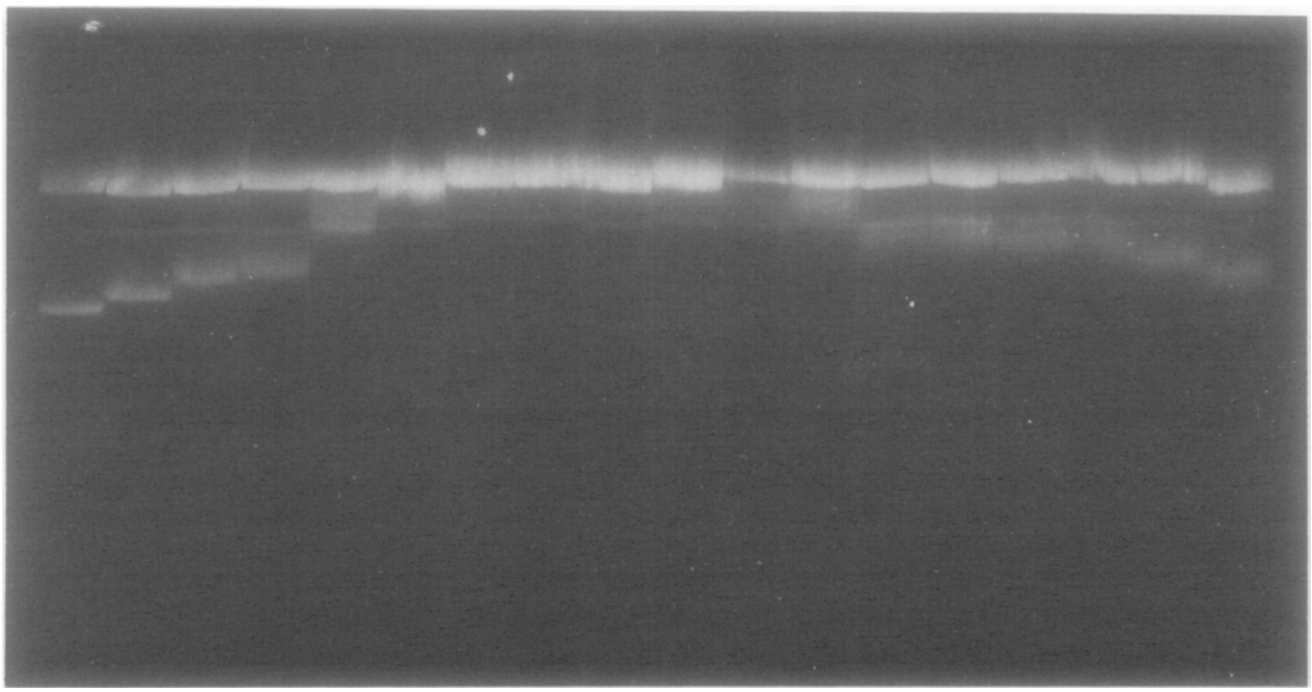

Higure 2: Dye titration of ColEI DNA

Direction of migration is from top to bottom. Ethidium bromide concentration increases in $0.01 \mu \mathrm{g} / \mathrm{ml}$ increments from left to right from 0.01 $\mu \mathrm{g} / \mathrm{ml}$ to $0.18 \mu \mathrm{g} / \mathrm{ml}$. 


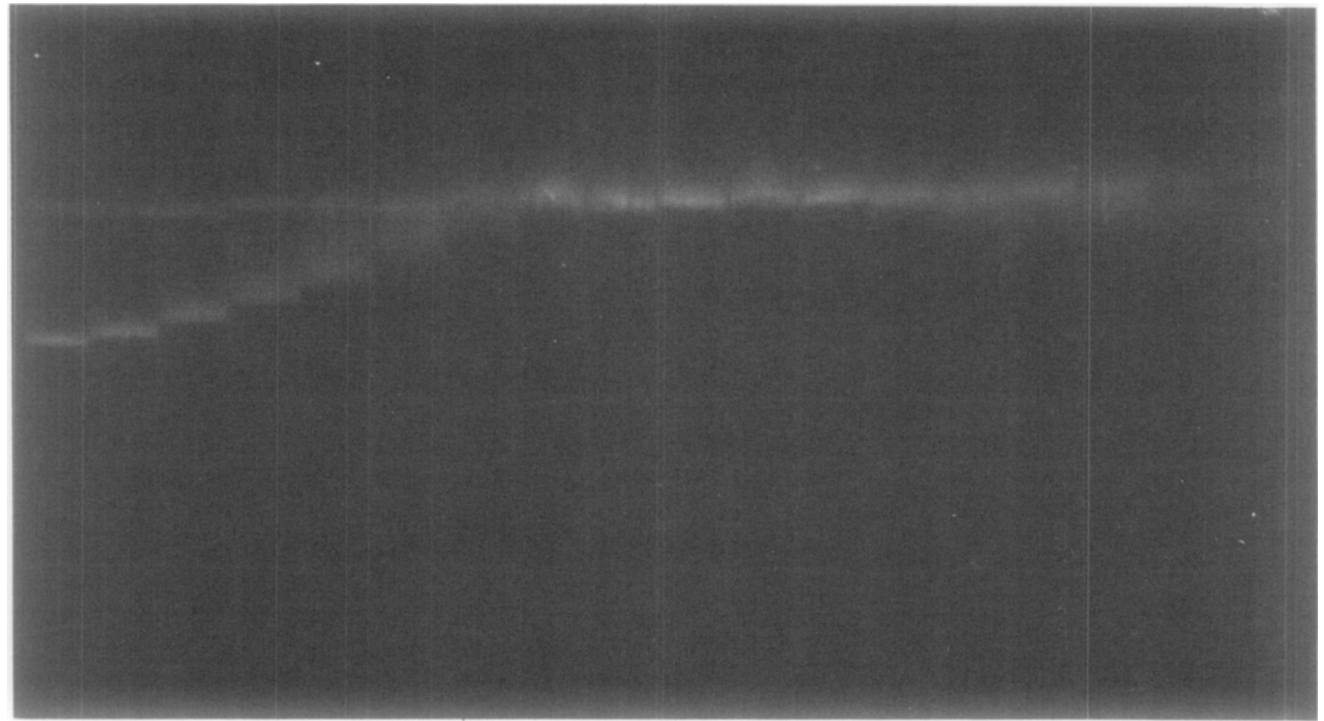

Figure 3: Dye titration of pSC101 DNA

Direction of migration is from top to bottom. Ethidium bromide concentration increases in $0.01 \mu \mathrm{g} / \mathrm{ml}$ increments from left to right from 0.01 $\mu \mathrm{g} / \mathrm{m} 1$ to $0.18 \mu \mathrm{g} / \mathrm{m} 1$.

dye concentration. The results are summarized in Table 1 . For ColE1 and pSC101 DNA, comigration of the covalently closed and nicked circular forms appeared to occur over a fairly broad range of free dye concentrations. This result may be attributable either to the short period of electrophoresis which may not adequately resolve partially unwound DNA molecules from fully unwound ones and form II, or it may be caused by heterogeneity in superhelix density in these DNA's (see below). In these cases, we have chosen for the calculations the mean ethidium concentration which results in comigration.

From the equation of Scatchard $(10), \nu_{c}$, the molar ratio of bound dye to nucleotide at $c^{\prime}$, can be evaluated when $c^{\prime}$ is expressed as a molar quantity. That is

$$
\nu_{c}=\frac{\nu_{m} \mathrm{Kc}^{\prime}}{1+\mathrm{Kc}^{\prime}}
$$

where $v_{m}$ is the maximum ratio of bound dye to nucleotide when the DNA is saturated. Hinton and Bode (11) have previously shown that $v_{\mathrm{m}}$ is 0.18 for 
TABLE 1

\begin{tabular}{l|c|c|c|c|c|c}
\hline DNA & $c^{\prime}(\mu \mathrm{g} / \mathrm{m} 1)$ & $v_{c}$ & $\sigma_{\sigma_{12}}$ & $\sigma_{o_{26}}$ & ${ }^{\tau}{ }_{12}$ & ${ }^{\tau} o_{26}$ \\
\hline SV40 & 0.05 & 0.035 & -0.023 & -0.050 & -12 & -26 \\
Co1E1 & 0.09 & 0.054 & -0.036 & -0.078 & -23 & -49 \\
pSC101 & 0.10 & 0.058 & -0.039 & -0.085 & -34 & -74 \\
\hline
\end{tabular}

Determination of superhelical densities and superhelical winding numbers for three circular DNAs.

Legend: The subscripts 12 and 26 refer to the duplex unwinding angle for ethidium bromide used in the calculations.

ethidium. The value $\mathrm{K}$ is the association constant for ethidium:DNA binding and was estimated by interpolation from the data of Hinton and Bode (11) to be $1.88 \times 10^{6} \mathrm{M}^{-1}$ in the electrophoresis buffer used for the titration.

The quantity $\nu_{c}$ can be used to calculate the superhelical density $\left(\sigma_{0}\right)$, defined as the number of superhelical turns per ten base pairs, of a closed circular DNA in the absence of ethidium. When $v$, the molar ratio of bound dye to nucleotide, equals $\nu_{C}$, and the unwinding angle, $\phi$, of ethidium is expressed in degrees, the relationship between $\nu_{c}$ and $\sigma_{0}$ is as follows (1)

$$
\sigma_{0}=\frac{-10 \phi \nu_{c}}{180}
$$

Previously, the unwinding angle due to ethidium binding was presumed to be $12^{\circ}$ (12). However, recent evidence suggests that in fact it may be $26^{\circ}$ (13). For the purposes of comparison, we have calculated $\sigma_{0}$ and $\tau_{0}$, the number of superhelical turns per molecule in the absence of dye, using both values for the ethidium unwinding angle. If $\phi$ is taken to be $12^{\circ}$, equation 2 reduces to

$$
\sigma_{0}=-0.67 \nu_{c}
$$

and when $\phi$ equals $26^{\circ}$

$$
\sigma_{\mathrm{o}}=-1.44 \nu_{\mathrm{c}}
$$

These values for the three DNAs titrated are presented in table 1. 


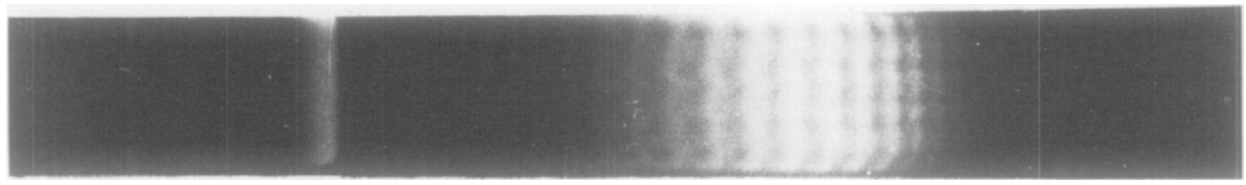

Figure 4: Separation of native SV40(I) DNA components

Electrophoresis was performed for $18 \mathrm{hrs}$ at $60 \mathrm{~V}$ on a vertical $24 \times 13 \mathrm{x}$ $0.4 \mathrm{~cm} 0.7 \%$ agarose $\mathrm{slab}$ gel. Ethidium bromide was included in both the ge1 and the buffer at a concentration of $15 \mathrm{ng} / \mathrm{ml}$. The direction of migration was from left to right. The left-most band is SV40(II).

Because of the short electrophoresis time, DNA which is partially relaxed is frequently poorly resolved into its several component species. In order to improve the resolution of the partially relaxed DNA, ethidium bromide was included in the electrophoresis buffer, allowing the time of electrophoresis to be extended. The results for SV40 are shown in figure 4. It is apparent that native covalently closed SV40(I) DNA is a collection of species. We have elsewhere (5) shown that this collection is a Boltzmann distribution of species. We have also shown that covalently closed relaxed SV40 DNA consists of a similar distribution of species, and similar observations have been made by others $(4,14)$.

\section{DISCUSSION}

The electrophoretic method we have described is an attractive alternative to the more time-consuming procedures previously used for characterization of covalently closed DNA. A complete determination of $c^{\prime}$ can easily be performed in one day. Its success relies on the assumption that ethidium bound to the DNA in the sample mixture dissociates rapidly to a level determined by the dye concentration in the gel before any detectable variation in migration rate can occur. We have shown in control experiments that this assumption is justified. With this simplification, the ethidium concentration in each gel may be considered the free dye concentration and may be used directly in subsequent calculations. It should be noted, however, that in the low ionic strength environment in which the titration is performed, the associa- 
tion constant $K$ is quite sensitive to small changes in ionic strength. The uncertainty in $\mathrm{K}$ probably represents the most significant source of error in this method.

It was of interest to compare the values of $\nu_{c}, \sigma_{0}$, and $\tau_{0}$ for SV40(I) DNA determined by this method with those reported by others using conventional ultracentrifugational procedures. Bauer and Vinograd (1), using a value of $12^{\circ}$ for the unwinding angle of ethidium, have reported values of -0.026 and -13 for $\sigma_{0}$ and $\tau_{0}$ respectively. Our values calculated with the same unwinding angle for ethidium are 5 to $10 \%$ lower, which would be expected, given the lower ionic strength of the solvent in our determination (15). This close correspondence of results for SV40 lends credence to our results for ColE1 and pSC101 DNA. The values of $\sigma_{0,12}$ for ColEl and pSC101 DNA fall within the range of values reported by Wang for other circular DNAs harbored by varlous strains of E. coll (16). Espejo and Lebow1tz (17), using a method similar to the one described here, have found values of $\sigma_{0,12}$ for SV40, PM2, and M13RFI DNA of $-.028,-.042$, and -.034 respectively.

The fact that it is possible to resulve discrete components of a covalently closed DNA when that DNA is partially relaxed indicates that the value of $\sigma_{o}$ obtained by any procedure actually represents an average value for that population of molecules.

\section{ACKNOWLEDGEMENTS}

This work was supported by Grant CA-13168 from the National Cancer Institute and a Rackham Faculty Grant to David A. Jackson. Robert DeLeys was the recipient of a Rackham Predoctoral Fellowship from the University of Michigan. We wish to thank Dr. Carolyn J. Collins for preparations of ColE1 and pSC101 DNA and Dr. Jack Lebowitz for communication of results prior to publication.

\section{REFERENCES}

1. Bauer, W., Vinograd, J. (1968) J. Mo1. Biol. 33, 141-171.

2. Smit, E., Borst, P. (1971) EEBS Letters, 14, 125-129.

3. Gray, H. B., Upholt, W. B., Vinograd, J. (1971) J. Mol. Biol., 62, 1-19. 
4. Keller, W., Wendel, I. (1974) Cold Spring Harbor Symposium on Quantitative Biology, 39, 199-208.

5. Deleys, R. J., Jackson, D. A. (1975) Subitted for publication.

6. Hirt, B. (1967) J. Mol. Biol., 26, 365-369.

7. Clewe11, D. B., Helinski, D. R. (1969) Proc. Nat. Acad. Sci. USA, 62, 1159-1166.

8. Cohen, S. N., Chang, A. C. Y., Boyer, H. W., Helling, R. B. (1973) Proc. Nat. Acad. Sci. USA, 70, 3240-3244.

9. Sharp, P. A., Sugden, B., Sambrook, J. (1973) Biochemistry, 12, 30553063.

10. Scatchard, G. (1949) Ann. N.Y. Acad. Sci., 51, 660-672.

11. Hinton, D. M., Bode, V. C. (1975) J. Biol. Chem., 250, 1061-1070.

12. Fuller, W., Waring, M. J. (1964) Ber. Bunsenges. Phys. Chem., 68, 805808.

13. Wang, J. C. (1974) J. Mol. Bio1., 89, 783-801.

14. Pulleyblank, D. E., Shure, M., Tang, D., Vinograd, J., Vosberg, H. (1975) Proc. Nat. Acad. Sci. USA, in press.

15. Wang, J, C. (1969) J. Mol. Biol., 43, 25-39.

16. Wang, J. C. (1969) J. Mo1. B1ol., 43, 263-272.

17. Espejo, R., Lebowitz, J. Anal. Biochem. in press. 